\title{
Prognostic Value of the Ocular Trauma Score in Traumatic Open Globe Injuries in the Philippines: A Five-Year Retrospective Study
} -Prognostic Value of the Ocular Trauma Score in Open Globe Injuries

\author{
Raymond Nelson C. Regalado*, Ruben Lim Bon Siong, Archimedes Lee D. Agahan, \\ Anthony F. Felipe \\ Department of Ophthalmology and Visual Sciences, University of the Philippines-Philippine General Hospital, \\ Manila, Philippines \\ Email: *monherbert@hotmail.com
}

How to cite this paper: Regalado, R.N.C., Siong, R.L.B., Agahan, A.L.D. and Felipe, A.F. (2018) Prognostic Value of the Ocular Trauma Score in Traumatic Open Globe Injuries in the Philippines: A Five-Year Retrospective Study. Open Access Library Journal, 5: e4224.

https://doi.org/10.4236/oalib.1104224

Received: November 30, 2017

Accepted: January 8, 2018

Published: January 11, 2018

Copyright $\odot 2018$ by authors and Open Access Library Inc.

This work is licensed under the Creative Commons Attribution International License (CC BY 4.0).

http://creativecommons.org/licenses/by/4.0/ (c) () Open Access

\begin{abstract}
PURPOSE: To determine the prognostic value of the Ocular Trauma Score (OTS) in patients with traumatic open globe injuries. METHODS: A retrospective chart review of patients with traumatic open globe injuries seen in a tertiary eye center in the Philippines from 2008 to 2013. Patients with traumatic open globe injuries who were at least 18 years of age upon first consult and with documented visual acuity at the first, third and sixth months of follow up were included in the study. The following data were collected: age, sex, occupation, manner of injury, type of injury, location of injury, presence of globe rupture, endophthalmitis, perforation, retinal detachment and afferent pupillary defect, and visual acuity (VA) at presentation, month 1, month 3 and month 6 . The OTS was computed from the available data. RESULTS: A total of 114 records were included. Open-globe (OG) injuries were more common in males (86.8\%), between 18 - 39 y/o (64.9\%) and who were manual workers (74.6\%). Most were occupation-related (64\%), seen within 1 - 3 days (55.3\%), and treated both medically and surgically (92.1\%). The most common type of OG injury was a penetrating laceration (82.5\%), had an initial VA of $4 / 200$ to light perception (57.9\%), had no afferent pupillary defect (APD) (84.2\%), and was located at zone I (73.7\%). The most common OTS anatomical factor seen, when present, was an APD (15.8\%). In all months, there was a significant positive correlation between OTS score and visual acuity. CONCLUSION: The OTS appeared to predict visual outcome as early as the first month post-injury, although correlation still exists at the $3^{\text {rd }}$ and $6^{\text {th }}$ months.
\end{abstract}




\section{Subject Areas}

Ophthalmology

\section{Keywords}

Ocular Trauma Score, Ocular Trauma, Open Globe Injury, Trauma

\section{Introduction}

Ocular trauma presents as one of the more common causes of emergency room consults worldwide. The United States Eye Injury Registry (USEIR) estimates that nearly 2.4 million eye injuries occur in the US annually, with about 1 million of them incurring a permanent and significant visual disability [1]. Present reports have different estimates of the incidence of hospitalization due to traumatic ocular injuries, from 8.1/100,000 in Sweden [2], 13.2/100,000 in USA [3], up to as high as 23.9/100,000 in Croatia [4]. In Asia, a nationwide survey in Singapore estimated the incidence rate of persons hospitalized with eye injury to be $12.6 / 100,000$ [5]. In the local setting, Valenton [6] noted that traumatic perforation of the cornea and sclera accounted for 3.3\%, or 483 cases, out of 14,553 cornea and external disease cases reviewed. Of these, $53 \%$ were younger than 20 years old. Students made up most of the trauma patients $(49.7 \%)$, followed by manual workers $(41.3 \%)$. The incidence of monocular blindness in the country $(61.3 \%)$ due to trauma was higher than that from other countries. In these cases, the rates of endophthalmitis (71\%) and sympathetic ophthalmia (2.7\%) were both exceedingly high.

Previously, a large inconsistency in ocular trauma classification existed between practitioners worldwide [7]. To address this issue, the International Society of Ocular Trauma (ISOT) devised an international terminology system [8] for categorizing ocular injuries, which was later called the Birmingham Eye Trauma Terminology (BETT) system [9]. In 1997, using the BETT system as a basis, Dr. Kuhn, together with Dr. Pieramici and other ocular trauma experts, formed the Ocular Trauma Classification Group (OTCG) to further describe globe injuries [10].

Although both the BETT and OTCG have greatly improved classification of ocular trauma for ophthalmologists to plan management, the ultimate goal is to provide visual rehabilitation for the patient. Numerous studies have been made to determine the factors that would greatly determine the expected final functional visual outcome. One of the most significant of these studies is a scoring system developed by Dr. Kuhn: the Ocular Trauma Score (OTS) [11]. Patients are given scores based on specific clinical findings, and the most likely visual acuity (VA) after six months may fairly be predicted (see Table 1 (a) and Table $1(\mathrm{~b}))$. Dr. Merca and Dr. Valbuena in 2014 reported that the OTS fairly predicted the visual outcome in $83 \%$ of the pediatric ocular trauma patients seen at a local tertiary eye center [12]. To date, there is no study done using this system 
Table 1. (a) The Ocular Trauma Score (OTS); (b) OTS groups and predicted VA at 6 months.

(a)

\begin{tabular}{ccc}
\hline DETERMINE RAW POINTS & VARIABLE & RAW POINT VALUE \\
\hline NLP & LP/HM & 70 \\
Initial Vision & $1 / 200-19 / 200$ & 80 \\
& $20 / 200-20 / 50$ & 90 \\
& $20 / 40$ or better & 100 \\
& Rupture & -23 \\
& Endophthalmitis & -17 \\
Other Findings & Perforating injury & -14 \\
& Retinal detachment & -11 \\
& APD & -10 \\
\hline
\end{tabular}

(b)

\begin{tabular}{ccccccc}
\hline \multicolumn{6}{c}{ CONVERT RAW POINTS INTO THE OTS AND IDENTIFY LIKELY VA AT 6 MONTHS (\%) } \\
\hline $\begin{array}{c}\text { Sum of raw } \\
\text { points }\end{array}$ & $\begin{array}{c}\text { OTS } \\
\text { GROUP }\end{array}$ & NLP & LP/HM & $1 / 200-19 / 200$ & $20 / 200-20 / 50$ & $20 / 40$ or better \\
\hline $0-44$ & 1 & 74 & 15 & 7 & 3 & 1 \\
$45-65$ & 2 & 27 & 26 & 18 & 15 & 15 \\
$66-80$ & 3 & 2 & 11 & 15 & 31 & 41 \\
$81-91$ & 4 & 1 & 2 & 3 & 22 & 73 \\
$92-100$ & 5 & 0 & 1 & 1 & 5 & 94 \\
\hline
\end{tabular}

on adult patients in our setting.

The main purpose of our study is to determine the prognostic value of the Ocular Trauma Score in patients with traumatic open globe injuries (OG). In these patients, there is a greater threat to vision and is more likely associated with ocular trauma-related hospitalization [6]. More specifically, we would like to provide demographic data of patients presenting with OG injuries seen in our institution. We also want to determine the time between initial consult and management of patients with open globe injuries and to correlate the predicted visual acuity according to the Ocular Trauma Score with the actual visual acuity at initial consult.

\section{Methodology}

After obtaining approval from the hospital's institutional review board, a retrospective chart review of all patients with traumatic OG injuries seen at the External Disease and Cornea Clinic of the Department of Ophthalmology and Visual Sciences, University of the Philippines-Philippine General Hospital from 2008 to 2013 was performed. Patients with traumatic open globe injuries who were at 
least 18 years of age upon first consult and with documented visual acuity at the first, third and sixth months of follow up were included in the study. Excluded were those with incomplete data, who were previously treated at a different institution and who did not complete at least 6 months of follow up.

Charts of known traumatic open globe injuries of the Cornea and External Disease Clinic from 2008 until 2013 were retrieved. Once the inclusion and exclusion criteria have been satisfied, the following demographic data were collected: age, sex, occupation, manner of injury, time to consult and type of management.

The injury was classified according to the BETT as one of the following: rupture, penetrating laceration, perforating laceration, and laceration with an intraocular foreign body (IOFB).

With regards to the OTCG, the injury was again classified as: rupture, penetrating, IOFB, perforating or mixed. In addition, the following injury characteristics were also recorded: initial Snellen VA, presence of an afferent pupillary defect (APD) and zone of injury (cornea to limbus, limbus to $5 \mathrm{~mm}$ posteriorly, and more than $5 \mathrm{~mm}$ posteriorly).

To compute for the OTS score, the presence of endophthalmitis and retinal detachment were also recorded. Lastly, VA at 1 month, 3 months and 6 months post-treatment were also recorded.

The main outcome measure is the OTS score, which was determined using the total sum of the raw points assigned for each following: initial VA and presence of rupture, endophthalmitis, perforation, retinal detachment and/or APD (Table 1(a) and Table 1(b)). Other outcome measures included frequency data according to age, sex, occupation, manner of injury, BETT classification, OTCG classification, time to consult, type of management, and visual acuities at 1 month, 3 months and 6 months post-treatment.

Descriptive data according to age, sex, occupation, manner of injury, BETT classification, OTCG classification, type of management, time to consult and computed OTS scores were grouped and analyzed into frequency distribution tables. Visual acuity at 1 month, 3 months and 6 months were correlated with the OTS groups by Pearson's correlation. Visual acuity at the $1^{\text {st }}, 3^{\text {rd }}$ and $6^{\text {th }}$ months of follow-up was also correlated with the OTS group using linear regression, where a p-value of less than 0.05 was considered significant.

\section{Results}

A total of 842 patient records were retrieved from the outpatient clinic. After review, only 114 patient records were eligible for this study.

The majority of the subjects were male (86.8\%), between 18 - 39 years of age (64.9\%) and employed in manual labor (74.6\%). Most of the patients included sought medical attention at our institution between 1 - 3 days after onset of injury (55.3\%). Almost all of the subjects underwent both medical treatment and surgical intervention (92.1\%) (Table 2).

The major type of injury according to the BETT classification was a penetrat- 
ing laceration $(82.5 \%)$, followed by a lacerating injury with a retained intraocular foreign body (10.5\%) (Table 3).

The most common type of injury according to OTCG was a penetrating injury (82.5\%), having an initial VA between $4 / 200$ to light perception (57.9\%), with a negative pupillary afferent defect (84.2\%) and located at zone I (73.7\%) (Table 4).

The majority of the subjects belonged to OTS group 3 (40.4\%) followed by OTS group 2 (20.2\%) (Figure 1).

The most common physical finding among those considered in the OTS was an afferent pupillary defect (15.8\%) (Table 5).

The most common visual acuities during each of the 3 follow-up periods are as follows: 4/200 to LP at 1 month and at least $20 / 40$ or better at 3 and 6 months. In all months, there was a statistically significant positive correlation between the OTS grade and corresponding VA, with a correlation coefficient highest at the first month $(\mathrm{R}=0.700, \mathrm{p}=<0.0001)$, followed by month $3(\mathrm{R}=0.633, \mathrm{p}=<$ $0.0001)$ then at month $6(\mathrm{R}=0.612, \mathrm{p}=<0.0001)$ (Tables $6-8$ and Figures $2-4)$.

Table 2. Demographical distribution.

\begin{tabular}{|c|c|c|c|}
\hline \multicolumn{2}{|c|}{ Demographical Distribution } & \multirow{2}{*}{$\begin{array}{c}\text { Total } \\
74\end{array}$} & \multirow{2}{*}{$\begin{array}{c}\text { Percentage }(\mathrm{n}=114) \\
64.9 \%\end{array}$} \\
\hline \multirow{3}{*}{ Age } & $18-39 \mathrm{y} / \mathrm{o}$ & & \\
\hline & $40-59 \mathrm{y} / \mathrm{o}$ & 31 & $27.2 \%$ \\
\hline & $60 \mathrm{y} / \mathrm{o}$ and older & 9 & $7.9 \%$ \\
\hline \multirow{2}{*}{ Sex } & Male & 99 & $86.8 \%$ \\
\hline & Female & 15 & $13.2 \%$ \\
\hline \multirow{4}{*}{ Occupation } & Student & 9 & $7.9 \%$ \\
\hline & Manual Worker & 85 & $74.6 \%$ \\
\hline & Office Employee & 5 & $4.4 \%$ \\
\hline & Unemployed & 15 & $13.2 \%$ \\
\hline \multirow{4}{*}{ Time to Consult } & Less than 24 hours & 9 & $7.9 \%$ \\
\hline & 1 - 3 days & 63 & $55.3 \%$ \\
\hline & 4 - 7 days & 28 & $24.6 \%$ \\
\hline & More than 1 week & 14 & $12.3 \%$ \\
\hline \multirow{2}{*}{ Management } & Medical only & 9 & $7.9 \%$ \\
\hline & Medical and Surgical & 105 & $92.1 \%$ \\
\hline
\end{tabular}

Table 3. BETT classification distribution.

\begin{tabular}{ccc}
\hline BETT Classification & Total & Percentage $(\mathrm{n}=114)$ \\
\hline Rupture & 5 & $4.4 \%$ \\
Laceration, penetrating & 94 & $82.5 \%$ \\
Laceration, perforating & 3 & $2.6 \%$ \\
Laceration, IOFB & 12 & $10.6 \%$ \\
\hline
\end{tabular}


Table 4. OTCG classification distribution.

\begin{tabular}{|c|c|c|}
\hline OTGG & Total & Percentage $(n=114)$ \\
\hline \multicolumn{3}{|l|}{ Type } \\
\hline Rupture & 5 & 4.4 \\
\hline Penetrating & 94 & 82.5 \\
\hline IOFB & 12 & 10.5 \\
\hline Perforating & 3 & 2.6 \\
\hline Mixed & 0 & 0.0 \\
\hline \multicolumn{3}{|l|}{ Grade } \\
\hline At least $20 / 40$ or better & 19 & 16.7 \\
\hline $20 / 50$ to $20 / 100$ & 12 & 10.5 \\
\hline $19 / 100$ to $5 / 200$ & 6 & 5.3 \\
\hline 4/200 to light perception (LP) & 66 & 57.9 \\
\hline LP to no light perception (NLP) & 11 & 9.6 \\
\hline \multicolumn{3}{|l|}{ Pupil } \\
\hline Positive & 18 & 15.8 \\
\hline Negative & 96 & 84.2 \\
\hline \multicolumn{3}{|l|}{ Zone } \\
\hline I & 84 & 73.7 \\
\hline II & 30 & 26.3 \\
\hline III & 0 & 0.0 \\
\hline
\end{tabular}

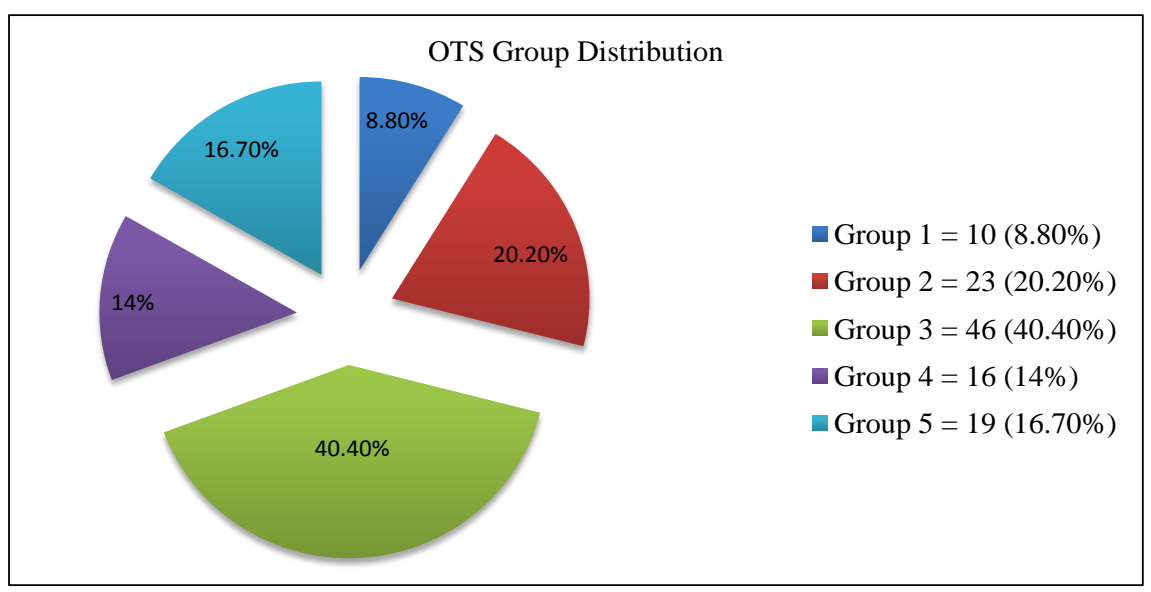

Figure 1. OTS group distribution.

Table 5. Distribution of OTS clinical findings.

\begin{tabular}{ccc}
\hline OTS & Total & Percentage $(\mathrm{n}=114)$ \\
\hline Rupture & 5 & 4.4 \\
Endophthalmitis & 13 & 11.4 \\
Perforation & 3 & 2.6 \\
Retinal Detachment & 14 & 12.3 \\
Pupil & 18 & 15.8 \\
\hline
\end{tabular}




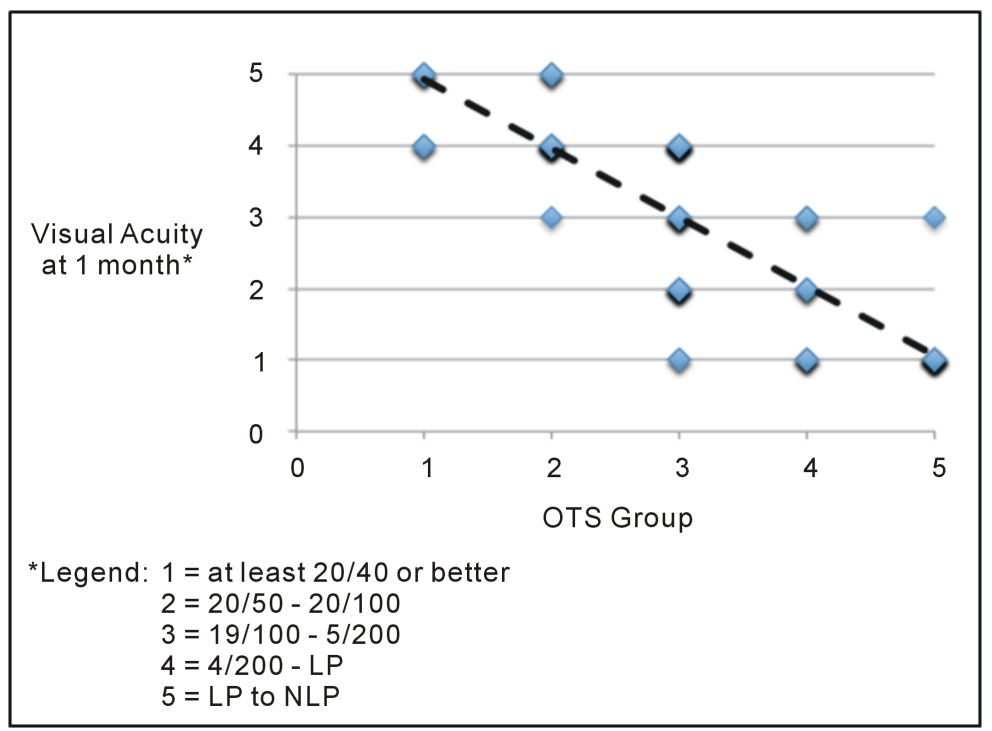

Figure 2. VA per OTS group at 1 month.

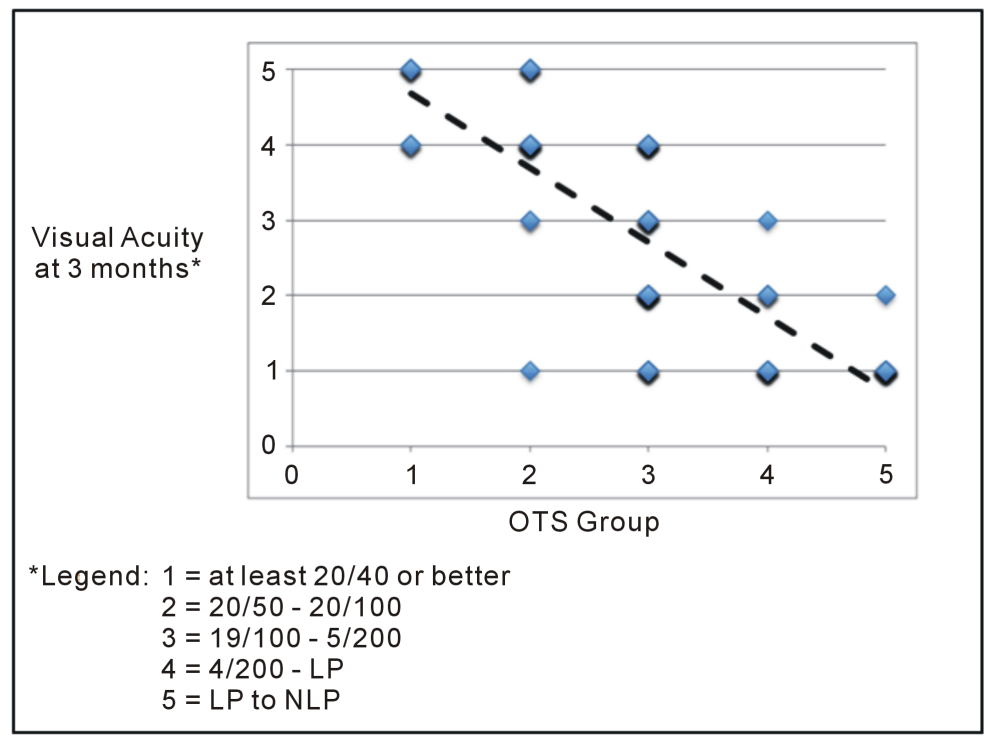

Figure 3. VA per OTS group at 3 months.

Table 6. Month 1 follow-up.

\begin{tabular}{|c|c|c|c|c|c|c|c|c|c|c|c|c|}
\hline \multirow{3}{*}{ VA } & \multicolumn{10}{|c|}{ OTS group } & \multirow{2}{*}{\multicolumn{2}{|c|}{ TOTAL }} \\
\hline & \multicolumn{2}{|c|}{1} & \multicolumn{2}{|c|}{2} & \multicolumn{2}{|c|}{3} & \multicolumn{2}{|c|}{4} & \multicolumn{2}{|c|}{5} & & \\
\hline & No. & $\%$ & No. & $\%$ & No. & $\%$ & No. & $\%$ & No. & $\%$ & No. & $\%$ \\
\hline At least $20 / 40$ or better & 0 & 0.0 & 0 & 0.0 & 3 & 10.7 & 7 & 25.0 & 18 & 64.3 & 28 & 24.6 \\
\hline $20 / 50$ to $20 / 100$ & 0 & 0.0 & 0 & 0.0 & 13 & 72.2 & 5 & 27.8 & 0 & 0.0 & 18 & 15.8 \\
\hline $19 / 100$ to $5 / 200$ & 0 & 0.0 & 1 & 6.2 & 10 & 62.5 & 4 & 25.0 & 1 & 6.2 & 16 & 14.0 \\
\hline 4/200 to light perception (LP) & 4 & 9.8 & 17 & 41.5 & 20 & 48.8 & 0 & 0.0 & 0 & 0.0 & 41 & 36.0 \\
\hline LP to no light perception (NLP) & 6 & 54.5 & 5 & 45.5 & 0 & 0.0 & 0 & 0.0 & 0 & 0.0 & 11 & 9.6 \\
\hline
\end{tabular}

Linear regression: $\mathrm{p}<0.0001 \mathrm{R}=0.700$. 


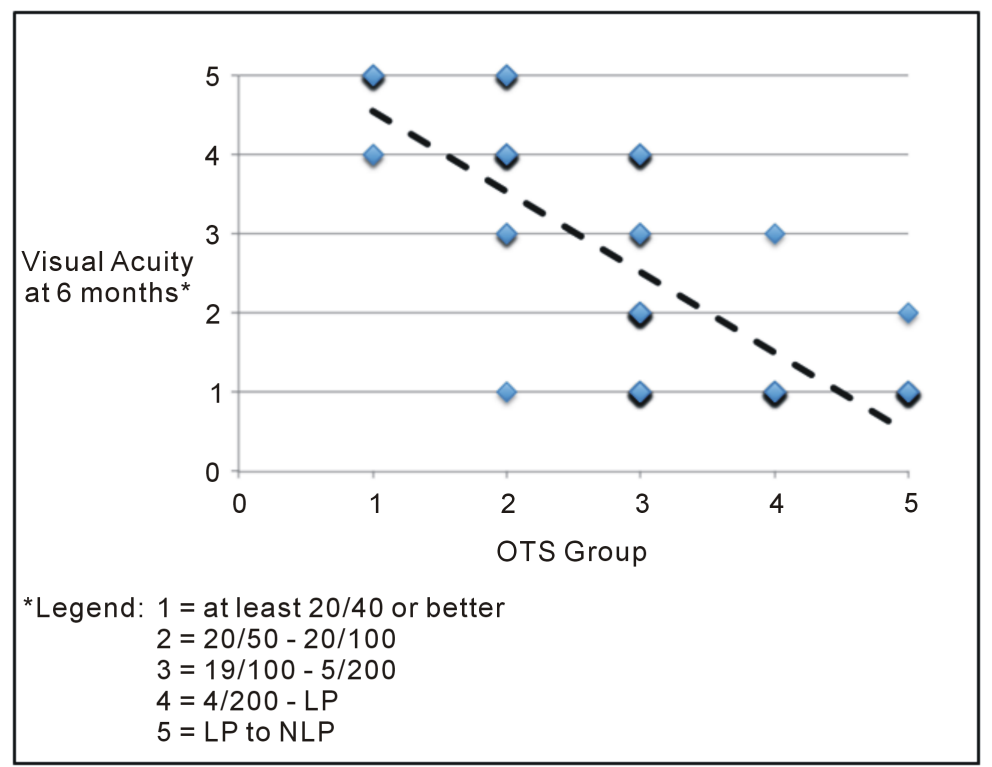

Figure 4. VA per OTS group at 6 months.

Table 7. Month 3 follow-up.

\begin{tabular}{|c|c|c|c|c|c|c|c|c|c|c|c|c|}
\hline \multirow{3}{*}{ VA } & \multicolumn{10}{|c|}{ OTS group } & \multirow{2}{*}{\multicolumn{2}{|c|}{ TOTAL }} \\
\hline & \multicolumn{2}{|c|}{1} & \multicolumn{2}{|c|}{2} & \multicolumn{2}{|c|}{3} & \multicolumn{2}{|c|}{4} & \multicolumn{2}{|c|}{5} & & \\
\hline & No. & $\%$ & No. & $\%$ & No. & $\%$ & No. & $\%$ & No. & $\%$ & No. & $\%$ \\
\hline At least $20 / 40$ or better & 0 & 0.0 & 1 & 2.6 & 8 & 21.1 & 11 & 28.9 & 18 & 47.4 & 38 & 33.3 \\
\hline $20 / 50$ to $20 / 100$ & 0 & 0.0 & 0 & 0.0 & 17 & 77.3 & 44 & 18.2 & 1 & 4.5 & 22 & 19.3 \\
\hline $19 / 100$ to $5 / 200$ & 0 & 0.0 & 2 & 16.7 & 9 & 75.0 & 1 & 8.3 & 0 & 0.0 & 12 & 10.5 \\
\hline $4 / 200$ to light perception (LP) & 4 & 13.3 & 14 & 46.7 & 12 & 40.0 & 0 & 0.0 & 0 & 0.0 & 30 & 26.3 \\
\hline LP to no light perception (NLP) & 6 & 50.0 & 6 & 50.0 & 0 & 0.0 & 0 & 0.0 & 0 & 0.0 & 12 & 10.5 \\
\hline
\end{tabular}

Linear regression: $\mathrm{p}<0.0001 \mathrm{R}=0.633$.

Table 8. Month 6 follow-up.

\begin{tabular}{|c|c|c|c|c|c|c|c|c|c|c|c|c|}
\hline \multirow{3}{*}{ VA } & \multicolumn{10}{|c|}{ OTS group } & \multirow{2}{*}{\multicolumn{2}{|c|}{ TOTAL }} \\
\hline & \multicolumn{2}{|c|}{1} & \multicolumn{2}{|c|}{2} & \multicolumn{2}{|c|}{3} & \multicolumn{2}{|c|}{4} & \multicolumn{2}{|c|}{5} & & \\
\hline & No. & $\%$ & No. & $\%$ & No. & $\%$ & No. & $\%$ & No. & $\%$ & No. & $\%$ \\
\hline At least $20 / 40$ or better & 0 & 0.0 & 1 & 2.0 & 16 & 32.0 & 15 & 30.0 & 18 & 36.0 & 50 & 43.9 \\
\hline $20 / 50$ to $20 / 100$ & 0 & 0.0 & 0 & 0.0 & 17 & 94.4 & 0 & 0.0 & 1 & 5.6 & 18 & 15.8 \\
\hline $19 / 100$ to $5 / 200$ & 0 & 0.0 & 3 & 37.5 & 4 & 50.0 & 1 & 12.5 & 0 & 0.0 & 8 & 7.0 \\
\hline 4/200 to light perception (LP) & 2 & 8.3 & 13 & 54.2 & 9 & 37.5 & 0 & 0.0 & 0 & 0.0 & 24 & 21.1 \\
\hline LP to no light perception (NLP) & 8 & 57.1 & 6 & 42.9 & 0 & 0.0 & 0 & 0.0 & 0 & 0.0 & 14 & 12.3 \\
\hline
\end{tabular}

Linear regression: $\mathrm{p}<0.0001 \mathrm{R}=0.612$.

\section{Discussion}

By far, most of the patients who presented with an open-globe injury were male manual workers in the adolescent to young adult age group. The most common 
occupations noted were construction workers and carpenters. This may seem different from Dr. Valenton's study, where it was noted that most of the patients were students [6]. One reason for this is that the previous study included all patients seen in the clinic, despite the age, as opposed to this study including only those older than 18 years old, who are more likely to be already working. What is alarming now is the high rate of injuries that were work-related. This data may indicate that there are still a number of manual labor companies and construction sites that do not prioritize ocular protection as part of their occupational health and safety programs.

With these patients usually belonging to the lower socio-economic class, it is not surprising to note that most of the patients did not seek medical attention within the day of injury. Most patients waited 1 - 3 days before coming in for consult, consistent with the previous study [6]. This is probably due to financial constraints and transportation difficulties.

The most common open-globe injury seen in our study is a penetrating injury, as defined by both the BETT and the OTCG. An intraocular foreign body was noted in 12 patients; in all of these, the object was a retained metal fragment. Globe rupture was seen in 5 cases; 4 of which were secondary to blunt trauma from a foreign object (hammer, wooden plank) and 1 case of mauling.

Almost all of the patients underwent some form of surgical intervention in addition to medical therapy. Eight of the 9 patients who only received topical medications had self-sealing lacerating injuries; one case had multiple healed lacerations and visual acuity was no light perception (NLP) at the time of presentation, thus no surgical intervention was done.

Most patients had poor Snellen visual acuity between 4/200 to light perception. This is may be due to a number of factors other than the corneal laceration itself. For one, there is a delay in the institution of management. Usually, the cornea is already edematous and opaque at the time of consult, which worsens the patient's vision. Another is that the lens may also be cataractous, thus contributing more to the blurring of vision even if the corneal component of the injury is not as extensive or seen far from the visual axis. It is good to note, however, that most patients presented without an afferent pupillary defect, signifying that there is a good chance for visual recovery even though there is poor visual acuity at initial presentation.

The OTS considered 1 functional variable and 5 anatomic variables to predict chance of visual recovery of ocular trauma patients at 6 months. Only less than $47 \%$ of the subjects had at least 1 of the associated anatomical injuries considered in the OTS study. This may imply that the poor VA more commonly seen in OG injury patients is more often not due to any one of these factors, but to other causes, which were very much treatable. Of the 5 anatomical considerations, the most common was an afferent pupillary defect, closely followed by retinal detachment and endophthalmitis. It is alarming to note that the incidence of endophthalmitis was still high in our setting. This may be linked to low so- 
cio-economic status and the delay in treatment commonly seen in government institutions. Computing for the final OTS score, the most common OTS group of these patients were OTS group 3 which signifies that most had good potential for visual recovery.

The higher OTS score correlated with better visual acuity in all months. This means that a visual acuity of worse than light perception was most commonly seen in OTS group 1, and visual acuity better than 20/40 was most commonly seen in OTS group 5. This is expected as patients in the higher OTS groups have less associated injuries and/or has retained better initial VA.

The percentage of patients with VA of at least $20 / 100$ or better steadily increased from initial consult up to 6 months. This shows that most of the patients with initially useful vision either retained good vision or even improved throughout their clinical course. In conjunction, the percentage of patients with a VA of worse than $4 / 200$ steadily declined. Being that the most common VA at presentation was $4 / 200$ to LP, it may be inferred that the causes of poor vision in these patients were mostly treatable, and restoration of vision was possible. Only 2 patients had worsening visual acuity seen by the end of 6 months. In these 2 patients, progressive worsening of the retinal detachment may have been the cause.

In all three periods of follow-up, there was a positive correlation between the OTS groups and the VA; the higher OTS group showed better VA. This result was comparable to that of the OTS study group. In addition to being comparable at 6 months, however, this present study also showed that the results of the OTS group were comparable even by the $1^{\text {st }}$ and $3^{\text {rd }}$ months of follow-up. This means that at presentation, the VA even at $1^{\text {st }}$ month of follow-up may fairly be predicted.

\section{Conclusion}

As evidenced in this study, the OTS provides a reliable scoring system to prognosticate adult patients presenting with open-globe injuries at the onset. Compared to the original OTS study, this scoring system appears to predict visual outcome as early as the first month post-injury, although correlation still exists at the $3^{\text {rd }}$ and $6^{\text {th }}$ months post-injury. It is fairly easy to use and only considers 6 factors. Having a copy of this scoring system for quick prognostication would allow efficient counseling not only for the patient, but also for the family and friends. It enables the clinician to fairly predict the most probable visual outcome of the patient, and from that, be able to formulate a cost-effective plan of management.

\section{Limitation}

One limitation of this study is that this study only aimed to prove prognostic value in patients with open-globe injuries. The OTS may also be applicable to patients with any type of ocular trauma, whether open or closed injuries. The 
authors recommend assessing the prognostic value of the OTS on all types of ocular trauma. Another limitation is the age of patients included in this study. Should younger patients have been included, demographic results may have coincided more with the findings of the Valenton study. The authors recommend doing a purely demographic study to assess the present incidence and prevalence of ocular trauma in our setting.

\section{Acknowledgements}

This research has been presented to the faculty of the Department of Ophthalmology and Visual Sciences, Philippine General Hospital in Manila, Philippines last 2015. No financial support was given to any of the authors of this study. There is no conflict of interest for any of the authors. All authors have no proprietary interest in any of the materials, medicines, or equipment mentioned in this study.

\section{Conflict of Interests}

No conflicting relationship exists for any of the authors.

All authors have no proprietary interest in any of the materials, medicines, or equipment mentioned in this study.

\section{References}

[1] US Eye Injury Registry, University of Alabama (UAB) Department of Ophthalmology 1988 (2014). https://useir.org/

[2] Desai, P., MacEwen, C.J., Baines, P. and Minassian, D.C. (1966) Incidence of Cases of Ocular Trauma Admitted to Hospital and Incidence of Blinding Outcome. British Journal of Ophthalmology, 80, 592-596. https://doi.org/10.1136/bjo.80.7.592

[3] Klopfer, J., Tielsch, J.M., Vitale, S., See, L.C. and Canner, J.K. (1992) Ocular Trauma in the United States, Eye Injuries Resulting in Hospitalization 1984 through 1987. Archives of Ophthalmology, 110, 838-842. https://doi.org/10.1001/archopht.1992.01080180110037

[4] Karaman, K., Gverović-Antunica, A., Rogosić, V., Lakos-Krzelj, V., Rozga, A. and Radocaj-Perko, S. (2004) Epidemiology of Adult Eye Injuries in Split-Dalmatian County. Croatian Medical Journal, 45, 304-309.

[5] Wong, T. and Tielsch, J. (1999) A Population-Based Study on the Incidence of Severe Ocular Trauma in Singapore. American Journal of Ophthalmology, 128, 345-351. https://doi.org/10.1016/S0002-9394(99)00167-1

[6] Valenton, M.J., Dyliacco, J.U. and Espiritu, C. (1993) Cornea and External Eye Disease Problems in the Philippines: A Twenty-Year Survey (1971-1991) Summary and Highlights. Philippine Journal of Ophthalmology, 22, 32-37.

[7] Kuhn, F., Morris, R., Mester, V. and Witherspoon, C.D. (2008) Terminology of Mechanical Injuries: The Birmingham Eye Trauma Terminology (BETT). In: Philipp, M., Ed., Ocular Traumatology, Springer-Verlag, Berlin Heidelberg, 3-10. https://doi.org/10.1007/978-3-540-33825-3_1

[8] Kuhn, F., Morris, R., Witherspoon, C.D., Heimann, K., Jeffers, J.B. and Treister, G. (1996) A Standardized Classification of Ocular Trauma. Graefe's Archive for Clinical and Experimental Ophthalmology, 234, 399-403. 
https://doi.org/10.1007/BF00190717

[9] Kuhn, F., Morris, R., Witherspoon, C.D. and Mester, V. (2004) The Birmingham Eye Trauma Terminology System (BETT). Journal Français D’Ophtalmologie, 27, 206-210. https://doi.org/10.1016/S0181-5512(04)96122-0

[10] Pieramici, D.J., Au Eong, K.G., Sternberg Jr., P. and Marsh, M.J. (1997) A System for Classifying Mechanical Injuries of the Eye (Globe) in Open-Globe Injuries. American Journal of Ophthalmology, 123, 820-831. https://doi.org/10.1016/S0002-9394(14)71132-8

[11] Kuhn, F., Maisiak, R., Mann, L., Morris, R. and Witherspoon, C.D. (2009) The Ocular Trauma Score (OTS): Prognosticating the Final Vision of the Seriously Injured Eye. In: Kuhn, F. and Pieramici, D., Eds., Ocular Trauma: Principles and Practice, Thieme, New York, 9-13.

[12] Merca, T. and Valbuana, M. (2014) Epidemiology and Visual Outcomes of Pediatric Ocular Trauma Cases in a Tertiary Hospital. Philippine Journal of Ophthalmology, 29, 27-32. 